\title{
Selected pharmacokinetic parameters for cefovecin in hens and green iguanas
}

Thuesen, Line Risager; Bertelsen, Mads Frost; Brimer, Leon; Skaanild, Mette Tingleff

Publication date:

2009

Document version

Publisher's PDF, also known as Version of record

Citation for published version (APA):

Thuesen, L. R., Bertelsen, M. F., Brimer, L., \& Skaanild, M. T. (2009). Selected pharmacokinetic parameters for cefovecin in hens and green iguanas. Poster session presented at European Association for Veterinary Pharmacology and Toxicology, Leipzig, Germany. 


\section{Selected Pharmacokinetic Parameters for Cefovecin}

\section{In Hens and Green Iguanas}

\section{Introduction}

- Cefovecin (ConveniatM, Pfizer Animal Health) is a semi-synthetic $3^{\text {rd }}$ generation cephalosporin recently developed for use in dogs and cats

- Cefovecin has in previous studies been shown to have an exceptional long elimination half-life in dogs $(136 \pm 10 \mathrm{~h} .)^{1}$ and cats $(166 \pm$ 18 h. $)^{2}$, making it suitable for antibacterial treatment with a 14-day dosing interval in these species

- A single-injection treatment will reduce stress in animal species sensitive to stress from handling and restraint such as reptiles and birds .

-The aim of this study was therefore to determine the plasma-half-life for cefovecin in hens and green iguanas to establish whether cefovecin is a suitable antibiotic for singleinjection treatment of bacterial infections in these species

\section{Materials and methods}

Pharmacokinetic parameters for hens were determined following subcutaneous and injections with $10 \mathrm{mg}$ cefovecin/ $\mathrm{kg}$ bodyweight in 8 juvenile Lohmann hens

-After injection 9 blood samples were taken from each hen at $5,10,15,20,30,40,60,90$ and 120 minutes after injection

Pharmacokinetic parameters for green iguanas were determined following subcutaneous injections with $10 \mathrm{mg}$ cefovecin/ $\mathrm{kg}$ bodyweight in 16 juvenile green iguanas of unknown origin

-Samples were taken at times $7,11,18 \mathrm{~min}$. after injection each time from 2 iguanas. Then the 16 iguanas were divided into 4 groups. At the times 20 min., 1, 4, 8, 16 and 24 h. after injection, blood samples were draw from one of the groups after a rotation scheme

A number of preliminary studies in randomly selected species of birds and reptiles were performed to investigate whether the pharmacokinetics found in hens and green iguanas were representative for these classes of animals

All blood samples were analysed by HPLC using the following method developed by us:

-Proteins in plasma samples were precipitated with $35 \%$ Trichloroacetic acid (3:1) and samples were centrifuged

-Supernatant were injected for HPLC analysis -The mobile fase consisted of $15 \%$ Acetonitrile and $85 \% 10 \mathrm{mM}$ Ammonium acetate pH 3

-The column used was a Supelcosil LC-8 DB $(3 \mu \mathrm{m})(3,3 \mathrm{~cm} \times 4,6 \mathrm{~mm})$ column (Supelco) -Components detected at wavelength 280 nm

References:

1.STEGEMANN M.R., SHERINGTON J., BLANCHFLOWER S., 2006. Pharmacokinetics and pharmacodynamics of cefovecin in dogs. 2.STEGEMANN M.R., SHERINGTON J., COATI N., BROWN S.A., BLANCHFLOWER S., 2006c. Pharmacokinetics of cefovecin in cats. J.Vet.Pharmacol.Ther. 29(6), 513-524

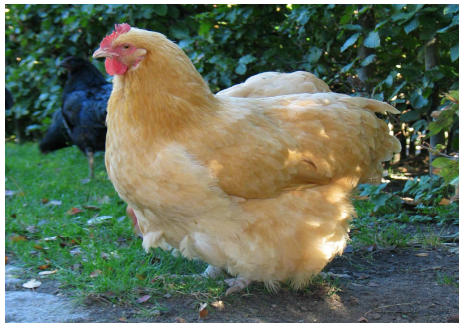

Figure 1: Hen (Gallus gallus (Linnaeus, 1758))

Subcutaneous injection

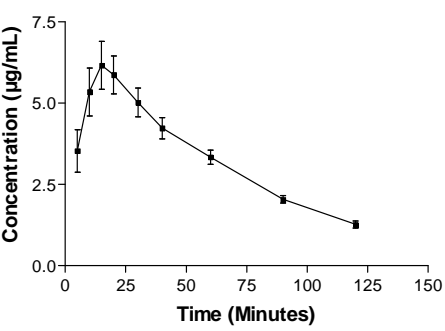

Figure 2: Mean concentrations of cefovecin in plasma following a single subcutaneous administration at $10 \mathrm{mg} / \mathrm{kg}$ b.w. in hen

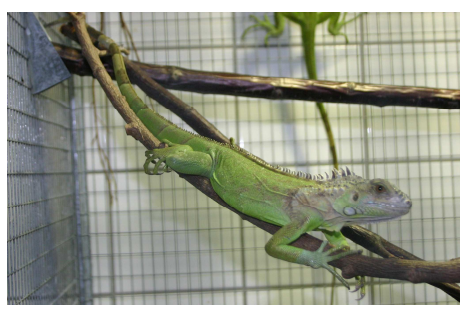

Figure 3: Green iguana (Iguana iguana (Linnaeus, 1758))

Subcutaneous injection

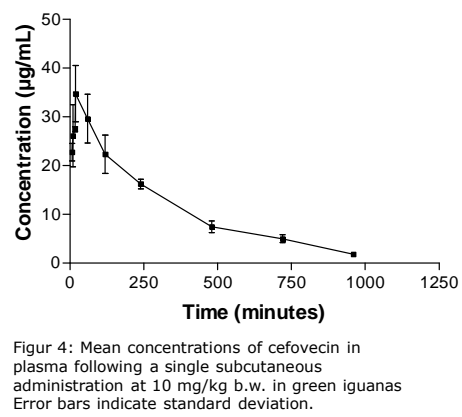

administration at $10 \mathrm{mg} / \mathrm{kg}$ b.w. in gre

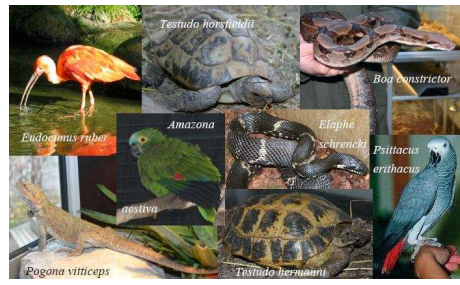

Figure 5: Species enrolled in the preliminary study

\section{Results}

Pharmacokinetic parameters for cefovecin in hens

- Cefovecin was characterized by rapid absorption with peak plasma concentration of $6 \pm 2 \mu \mathrm{g} / \mathrm{mL}$ within $20 \mathrm{~min}$. of subcutaneous injection

-Mean plasma half-life was $52 \pm 16$ minutes after subcutaneous injection

-Volume of distribution was $1.6 \pm 0,5 \mathrm{~L} / \mathrm{Kg}$ and clearance was $21 \pm 3 \mathrm{~mL} / \mathrm{min} / \mathrm{Kg}$ (Both parameters calculated with the bioavailability set to be $100 \%$ )

Pharmacokinetic parameters for cefovecin in green iguanas

-Mean plasma half-life was 3.9 hours after subcutaneous injection

-Volume of distribution was $0.3 \mathrm{l} / \mathrm{Kg}$ and clearance was $53 \mathrm{~mL} / \mathrm{hour} / \mathrm{Kg}$ after subcutaneous injection (Parameters calculated with the bioavailability set to be $100 \%$ )

\section{Discussion}

-Concentrations of cefovecin in plasma obtained from bird species in the preliminary study were similar to concentrations in hens

- More dissimilarities were observed between reptile species, indicating a larger variance in pharmacokinetic parameters in these species

-Possible reasons for variation of pharmacokinetics for cefovecin in different species include:

- diversity in P450 isoenzymes

- variations in protein binding

- renal physiologic and anatomic differences

-There is still a good possibility that there are other stress sensitive animal species for which cefovecin will be a good choice for antibiotic treatment

-There is a need to identify broad-spectrum antibiotics with long elimination half-lives that can be used in wildlife and zoo animals to reduce the stress these animals experience in relation to medical care

\section{Conclusion}

- Cefovecin is not suitable for treatment of bacterial infections with a single-injection dosing regime in hens or green iguanas.

-It is unlikely that cefovecin is suitable for treatment of bacterial infections $i$ any species of birds

-Cefovecin may be indicated for treatment in some but not all species of reptiles

-More studies on cefovecin are needed 